\title{
WOMEN AND SPORT
}

\author{
Nenad Ponorac ${ }^{1}$, Stanislav Palija ${ }^{2}$, and Mira Popović ${ }^{3}$ \\ ${ }^{1}$ School of Medicine, University of Banja Luka, Bosnia and Herzegovina \\ ${ }^{2}$ Institute of Physical Medcine and Rehabilitation "Dr Miroslav Zotović", Banja Luka, \\ Bosnia and Herzegovina \\ ${ }^{3}$ Institute of Occupational and Sports Medicine of The Republic of Srpska, Banja Luka, \\ Bosnia and Herzegovina
}

\section{SUMMARY}

Regular physical activity is important for the health of both sexes. However, the physiological, anatomical, psychological and socio-cultural specificities of women require special considerations in all aspects of their sports. Puberty brings gender differences that result from different sexual functioning of endocrine axis. Despite the identical mechanisms of adaptation to physical activity, sexually mature women and men have inherited anatomical and physiological differences in body composition, aerobic capacity-building and muscle strength. In particular, it relates to the more complex female reproductive system. The female reproductive system is a functional part of the human body most sensitive to stress caused by heavy physical exertion. The most common disorders whose risk was significantly increased in physically active women are eating disorder, disturbed menstrual cycle, infertility, intimidated fractures, rupture of the anterior cruciate ligament, or even death. Mainly those are result of blunders and ignorance. Fortunately, they are largely preventable.

Key Words: physical activity, eating, menstrzal cycle, intimedated fractures, female athlete triad.

\section{INTRODUCTION}

Historical medical record U.S. Surgeon General's Report on Physical Activity and Health gave solid scientific evidence that regular physical activity is very important for the health of both men and women, with the recommendation of active participation in all aspects of physical activity and sports (U.S. Department of Health and Human Services, 1996). However, the physiological, anatomical, psychological and socio-cultural specificities of females require special considerations in all aspects of their sports (Greydanaus \& Patel, 2002). Women now have available all sports venues, but it was not always the case. The first Olympic Games (776 B.C.) were privilege and pleasure of men only. Women have sought their satisfaction in the Games in honour of the goddess Hera, the protector of women of that age. First modern Olympic Games, held in 1896, had a similar trend for women, meaning they were without the possibility to participate (Ponorac, 2008).

Beginning of the 20 century made progress in this regard and women were slowly included in a broader range of sporting activities. That is how, slowly but surely, they became a part of sporting life. On the other Olympics 12 women were competing in tennis and golf, so-called upper class sports (Pfister, 2000). The increase in female participation in sports happened in the second half of the 20th century, and on 23 July 1972 dawned another 8 March, this time in sports. U.S. President Nixon signed the famous Title IX (Education Amendment Act) which provides that "no person in the United States may not, on the basis of sex, be excluded from participation in, denied the benefits of, or be subjected to discrimination in any educational program or activity financed by public funds "(Mitchell \& Ennis, 2007).

Since the signing of the Title IX until the 80's of the last century, the number of awarded scholarships 
and so women actively involved in the sport as well, has increased by $700 \%$, and during the 90's for another $50 \%$. At the beginning of the new millennium, one of three high school students in the United States was actively involved in the sport as opposed to one of 27 in 1972 (Ireland \& Ott, 2004). The London 2012 achieved yet another record, a record number of participants, $46 \%$ of over 10.000 participants, while in 1908 the ratio was 53:1 in favour of men.

Playing sports gives women many benefits. It is proven that girls active in sports have better success in school, are less likely to face unwanted pregnancies in their teen age, have higher self-esteem and selfconfidence, more easily and more often enrol in colleges and universities, and less frequently have problems with drug abuse and dependence diseases. Exercises with weight load have inestimable benefit to the development and maintenance of bone mass in females at all ages (Hagen, 2005).

However, nature has not signed the declaration on gender equality in sport. As for the physical activity a long time ago people said that women are "the weaker gender". Along with the trend that all sports can be practiced for the sake of gender equality, in women it leads to the development of many features that evolutionarily characterized men. According to Nikola Grujic, during the evolution biology already made gender differences in the relation to especially their reproductive role, so the "interference in her affairs" responses with the consequences that are unforeseen and which price is extremely expensive in every case. This price can be paid as an eating disorder, disturbed menstrual cycle, infertility, intimidated fractures, rupture of the anterior crossed ligament, or even death. Is it worth? These aspects will be discussed in the following sections.

\section{SPECIFIC PHYSIOLOGICAL AND ANATOMICAL CHARACTERIS- TICS OF FEMALE ATHLETES}

Since today most sports are equally available to both genders, the sports results are often surprising. Differences in world records in men's and women's events are not as drastic and they vary within a range of $15 \%$. For science, especially of sports, raise new questions, whether it is the result of real biological differences between the genders and where is the fine line between physiology and pathology?

Pre-puberty boys and girls have comparable physical abilities, in general, they can play in the same teams and compete against each other until the age of 10 (Ireland \& Ott, 2004).
Puberty causes significant differences between the genders as a result of various sexual functioning of endocrine axis, and the presence of testosterone and one with oestrogen and progesterone on the other. In particular, it relates to the more complex female reproductive system.

Despite the identical mechanisms of adaptation to physical activity, sexually mature women and men have inherited anatomical and physiological differences that are reflected in body composition, aerobic capacity and muscle strength.

Body composition of women is characterized by lower total mass, a lower percentage of muscle tissue and increasing percentage of fat.

The smaller muscle mass mainly refers to small diameter of single muscle fibre. This is logical given the anabolic effect of testosterone and a slight predominance of type I muscle fibres, which have a smaller diameter. Thus, women have less ability to generate absolute power, especially in the upper extremities, which is as much as 50\% less than men. But when power is expressed in relative muscle mass, body mass and cross-section of muscle those differences are significantly reduced. Women have an average of 5-15\% less aerobic capacity. These differences do not stem from differences in muscle fibres (capillarization, mitochondrial content and enzymes of aerobic metabolism) than in the ability to receive oxygen. Women have a lower stroke volume and thus cardiac output. The smaller blood volume, hematocrit and haemoglobin contribute to a lower aerobic capacity. This difference is also attributed to testosterone, which besides an anabolic effect also serves as a stimulus for erythropoietin (Kenney, Wilmore, \& Costil, 2012)

A higher percentage of body fat females owe to estrogens. It stimulates the disposal of fat in the subcutaneous tissue, breast tissue, especially in the gluteus region and thighs. High lipoprotein lipase activity during puberty causes the deposition of fat in these areas which is hard to lose. Along with the expansion of the pelvis this causes a distinctive feature of the female figure. Often this look is a source of great dissatisfaction with women, with high neglects of its real role. During the last trimester of pregnancy and throughout lactation activity of lipoprotein lipase is reduced and decomposition begins, which suggests that fat is stored here only as an energy support to pregnancy and breastfeeding and extension of our species (Bjorntorp, 1986).

The most striking anatomical difference is related to the dimensions of the pelvis, which is by a greater width subordinated to the birth process. Consequently it is altered to anatomical position and man- 
ner of movement of the lower limbs (Ireland \& Ott, 2004). The so-called Miserable Misalignment Syndrome is a set of anatomical variations of the lower extremities, which probably make women predisposed to instability, knee pain and finally frequent anterior cruciate ligament injury (Myer \& Ford, 2004). In extreme cases it is composed out of femoral anteversion, accompanied by a quadriceps angle (Q-angle) greater than 15 degrees, external tibial torsion, increased foot pronation, flattening foot (pes planus) and hypoplastic musculus vastus medial obliqus (Figure 1). This syndrome, with differences in neuromuscular response, hormonal status (effect of estrogen receptors on ligaments), and of course, differences in training, causes up to 7 times more common injuries of anterior cruciate ligament and patellar syndrome with female than male athletes (Ireland \& Ott, 2004).

\section{MEDICAL \\ ASPECTS OF FEMALE SPORTS}

\section{Female athlete triad}

Increasing number of females participating in sports has increased the risk for any negative consequences that follow sports. The danger is accentuated because women are starting to compete in the endurance sports without any limitations. A number of typically female profile sporting disciplines with a strong emphasis on the external appearance of a woman is also increasing.

The female reproductive system is a functional part of human body most sensitive to the stress caused by hard physical labor and sports (Yeager, Agostini, Nattiv, \& Drinkwater, 1993).

FIGURE 1

Misalignment Syndrome.

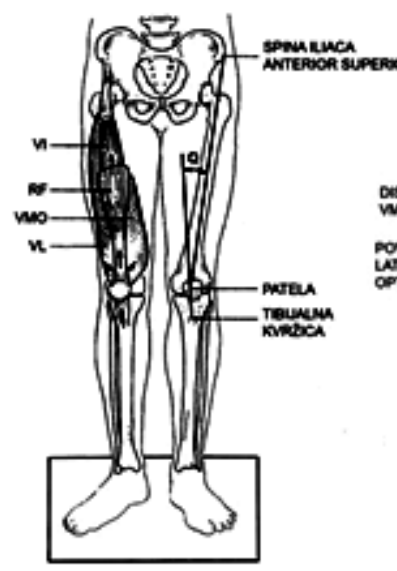

In the early 90 `s of the last century the connection between women athlete eating disorders, menstrual cycle disorders and disorders of bone metabolism (mineralization) became apparent. Yeager et al. (1993)included them in the syndrome known as the Female Atblete Triad. Since the gymnast Christy Henrich died in 1994 in the age of 22 and with $29 \mathrm{~kg}$ in weight due to a bizarre remark of her trainer that she is "too fat" for the Olympic team, the medical community turned on red warning light for each of the individual symptoms of the Triad. The potential impact of each disorder or a combination of several of them has proven to be harmful for the health and success in sports (Drinkwater, Loucks, Sherman, Sundgot-Borgen, \& Thompson, 2005).

Three angles of the Triad are mutually multiply intertwined by physiological and psychological mechanisms, and the presence of one of the symptoms requires immediate testing for the presence of others (Barrack, Ackerman, \& Gibbs, 2013).

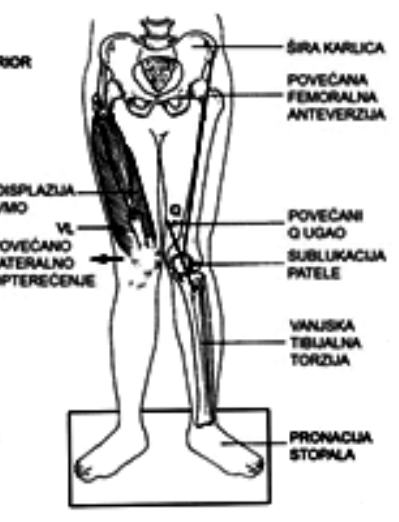

\section{Eating disorders}

Eating disorders are disorders of the continuous model. It ranges from abnormal eating babits in order to reduce weight to serious clinical conditions that result even with death (Goldstein, Dechant, \& Bere$\sin , 2011)$.

In the continuum there are clinical disorders $A n$ orexia Nervosa, Bulimia Nervosa and special category Eating disorders not otherwise specified - EDNOS ("Diagnostic and statistical manual of mental disorders", 1994).

- Anorexia Nervosa is the most severe eating disorder that often results in fatal outcome. The sick person sees himself "too fat" and suffers from a fear of weight gain, although it often weights even $15 \%$ less than the expected.

- Bulimia Nervosa is characterized by cycles of restrictions in diet or fasting to track the phases of uncontrolled overeating for so-called psy- 
chological hunger, followed by a phase of cleaning. Cleaning includes induced vomiting, use of laxatives or diuretics (purging type) and starvation and extreme exercise (non-purging type), with the aim of returning to the old state. Women athletes with bulimia are often normal weight (Sundgot-Borgen \& Larsen,1993).

- Eating disorders not otherwise specified (EDNOS) apply to a wide range of eating disorders that do not meet all the criteria of clinical disorders. People have normal weight; however, there is a preoccupation with diet, body weight, shape and body composition.

- Subclinical forms of eating disorders exist in many cases of eating disorder where woman athlete is trying to reduce body weight or fat percentage by exposing herself to the restrictions on food (diet), avoiding certain food or practicing other abnormal eating habits without reaching the criterion for eating disorders (Sabatini, 2001).

- Low Energy Availability is the state in sports that is caused by decreased energy intake, diet or significantly increased energy use through physical activity. Energy deficit without eating disorder is often associated with disturbances of the menstrual cycle and presents a "starting point" for the development of the Triad.

The exact percentage of athletes with eating disorder is difficult to determine because it is a symptom of Triad that is often overlooked and unspoken. Studies show a higher incidence of eating disorders in athletes compared to non-athletes, women athletes compared to men athletes (Coelho et al., 2013). Female athletes who participate in sports with strong aesthetic appearance (dance, gymnastics, ballet), endurance sports (athletics, swimming, cycling) and those that compete in weight categories (martial arts) are at the higher risk level. The incidence of anorexia and bulimia by DSM-IV criteria in normal population ranges from $1 \%$ to $3 \%$, while the percentage of eating disorders in athlete population ranges from 15\% to $62 \%$, depending on the type of sports (SundgotBorgen \& Torstveit, 2004).

Literature states following possible causes for eating disorders:

- Diets - Restrictive diet to reduce weight is the primary cause for the development of eating disorders.

- Calorie Deficit. The rapid increase in the volume of training can cause a calorie deficit.

- Start of sport-specific exercise before puberty. Female athletes with identified eating disorders began with their careers earlier than other athletes
(Thomson \& Sherman, 1999). If sport-specific exercise begins before puberty, rapid growth and development can lead to a mismatch between the body shapes and requires of the chosen sport, which as a consequence can have a change of body composition by strong restriction diet (Deimel \& Dunlap, 2012).

- Traumatic experiences. The most common traumatic experiences that influence the development of eating disorders are changes or loss of coach and athlete's illness or injury, manifested by difficulties in training. This often leads to weight gain, or in some cases, the fear of it, leading to subsequent compensatory reduction of food intake. Possible trauma are also random interruptions and comments regarding physical appearance, poor school success, problems with your partner or parents, death of a friend, and finally, and often, sexual abuse by a coach (Drinkwater et al., 2005).

- Beliefs that reduce of body weight or fatpercentage leads to improved physical fitness. The initial weight loss can often improve physical fitness. This initial success can stimulate the athlete to continue with mass loss until the very development of eating disorder. Athletes often commented, "It just happened, it was never planned".

Coaches often give a contribution to this risk factor by stimulating this unhealthy and unnatural way of improving physical fitness of their athletes.

Official stance of the IOC is that coaches cannot assess body composition of athlete nor make suggestions. It is recommended that they can only express their concern or attitude about it and direct athlete to a doctor or dietitian-nutritionists specialist. He will, after careful consideration and review, together with the athlete decide on the measures on how to correct body mass (Ibid).

Health effects that eating disorders leave behind affect many systems, and mortality caused by anorexia nervosa, as the most severe one, is $6 \%$.

The early effects are decrease in basal metabolic rate, extraction of glycogen from muscle and liver, decreased in muscle mass and dehydration. This makes the athlete more susceptible to fatigue and musculoskeletal injuries due to disturbed endurance, strength, movement coordination and concentration. Electrolyte imbalance can lead to serious heart rhythm disorders, and endocrine system and thermoregulation are also affected. Bulimics suffer from severe gastrointestinal problems and enlargement of parotid gland and erosion of tooth enamel as a result of frequent vomiting (Otis, Drinkawater, Johnson, Loucks, \& Wikmore, 1997). 
Late effects are estrogen deficit and menstrual cycle disorder, which presents the link between first two symptoms of Triad.

\section{Menstrual cycle disorders}

Monthly menstrual cycle is a complex interaction between the endocrine and reproductive system of a women. Normal, regular menstrual cycle (eumenorrbea) lasts 24-36 days, an average of 28 days. It most commonly begins with menarche - first menstrual bleeding in the average age of 12.88 years in North America and 13 in Europe (Ibid).

A wide range of menstrual cycle disorders can be found in physically active women, especially athletes.

- Oligomenorrbea as a term refers to irregular menstrual cycles with bleeding interval longer than 36 days or 3 to 6 times per year.

- Primary amenorrbea is defined as the non-appearance of menstrual cycle by age of 16 in girls with the presence of secondary sexual characteristics or non-menstrual bleeding and by 14 years with the underdevelopment of secondary sexual characteristics.

- Secondary amenorrhea is defined as the absence of three or more consecutive menstrual cycles after menarche in the absence of pregnancy, or less than three periods per year (Nativ et al., 2007).

Frequency of menstrual dysfunctions with normal, adult population ranges from $2 \%$ to $5 \%$, while in sports it varies significantly depending the type of sports, competition rang and a lot of other parameters, and they range from $20 \%$ to incredible $70 \%$ in certain samples (Elford \& Spence, 2002). In general, the highest frequency was noticed in endurance sports, sports with weight categories and sports with emphasized aestetic performance. Ponorac derived similar results when he examined the sample of elite national women athletes. The frequency of all menstrual dysfunctions was greater in groups of athletes in relation to the control group. Primary amenorrhea was determined in $8.33 \%$ and oligomenorrhea in $13.09 \%$ of female athletes (Ponorac, Rašeta, Radovanović, Matavulj, \& Popadić-Gaćeša, 2011)

One of the most appropriate mechanisms of menstrual disorders in sports includes also eating disorders. Energy access/availability is defined as the energy calorie intake minus the energy consumed during physical activity. The imbalance between energy expenditure during exercise and caloric intake causes the body to receive information about the inadequate energy storage necessary to support reproduction and fetal development. The body then enters a state of "energy conservation" and the re- productive system, as a luxury feature, is very effectively extinguished with the goal of self-defense, or by informal terminology enters a "shut down" state. This type of amenorrhea is named Functional hypothalamic amenorrhea (HPA), and often as a synonym appears the term Sports amenorrhea (Catherine \& Gordon, 2010).

Amenorrhea is neither desired nor "normal" condition caused by sports. In amenorrheic female athletes ovulation is difficult to predict, what causes the possibility of unwanted pregnancy, which is especially difficult in the season of important events. The risk of endometrial hyperplasia and adenocarcinoma of the uterus is also increased.

However, the most severe consequence, and at the same time the third symptom of the Triad, is bone mass loss and subsequent osteoporosis (Thein-Nissenbaum, 2013).

\section{Disorder of bone metabolism (Osteoporosis]}

Bone is a metabolically active tissue, and bone remodeling involves the reabsorption and bone formation, a process that takes a lifetime. The balance between these two processes enables the maintenance of overall bone mass and bone morphology. At least $60-70 \%$ of the maximum bone mass is gained during puberty and adolescence, the so-called "window of opportunity", and to $90 \%$ by the end of the second decade of life (Barnekow-Bergkvist, 2005). Positive effects for reaching the maximum (peak) bone mass of young female come from various forms of physical activity, the level of growth hormone and IGF-I, and preserved physiological menstrual cycle (Jurimae \& Jurimae, 2008).

Low energy availability with or without eating disorder, amenorrhea and osteoporosis, individually or connected as Triad, present a significant health risk for a women bone. Estrogen deficit caused by the HPA undermines the achievement of maximum bone mass in young women and can significantly reduce the positive effect of physical activity on bone (Ducher \& Eser, 2009). Consequentially arises the osteoporosis, one of the most difficult bone diseases, when mineral content and bone may be so reduced that stress fractures occur even after a minimal load (Barrack et al., 2013).

Additional deficit of calcium and protein due to an eating disorder, plus delayed menarche, are more favorable to premature osteoporosis of female athlete.

In accordance with the latest recommendations, the primary treatment of Triad begins with fight against eating disorders. As the best solution proved to be an increase in energy intake and reduced training volume in order to increase the energy level to 
the extent that would allow reestablishment gender shaft of a woman. That also solves the third symptom, by stopping the loss of bone density, including osteoporosis (Ibid).

\section{CONCLUSION}

In response to one of these questions at the beginning of the text, we can conclude the following. Most of these medical conditions that often affect physically active women and female athletes have a high price for sports, essentially healthy activity. Also, the intention was to show the delicate border where sports ends and medicine begins. Fortunately, most of the described disorders are the result of errors during the training process and can be prevented with certain measures. It has long been said that "prevention is better than the cure". Introducing female athletes, coaches, parents and doctors with this problem is also the first step.

\section{REFERENCES}

Barnekow-Bergkvist, M., Hadberg, G., Pettersson, U., \& Lorentzon, R. (2005). Relationships between physical activity and physical capacity in adolescent females and bone mass in adulthood. Scand J Med Sci Sports, 14, 1-9.

Barrack, M. T., Ackerman, K. E., \& Gibbs J. C. (2013). Update on the female athlete triad. Curr Rev Musculoskelet Med, 6(2), 195-204. doi: 10.1007/s12178-013-9168-9; PMid: 23613226

Bjorntorp, P. (1986). Fat cells and obesity. In K. D. Bronwell (Ed.), Handbook of eating disorders (pp. 88-98). New York, NY: Basic Books.

Catherine, M., Gordon, M. D. (2010). Functional Hypothalamic Amenorrhea. $N$ Engl J Med, 363, 365-371.

Coelho, G. M., de Farias, M. L., de Mendonça, L. M., de Mello, D. B., Lanzillotti, H. S., Ribeiro, B. G., Soares Ede, A. (2013). The prevalence of disordered eating and possible health consequences in adolescent female tennis players from Rio de Janeiro, Brazil. Appetite, 64, 39-47. doi: 10.1016/j.appet.2013.01.001; PMid: 23318655

Deimel, J. F., \& Dunlap, B. J. (2012). The female athlete triad. Clin Sports Med, 31(2), 247-254. doi: 10.1016/j.csm.2011.09.007; PMid: 22341014

Diagnostic and statistical manual of mental disorders, DSM-IV (1994). In: Diagnostic and statisticl manual of mental disorders, DSM-IV.
American Psychiatric Association (1st ed) Washington D.C.

Drinkwater, B., Loucks, A., Sherman, R. T., Sundgot-Borgen, J., Thompson, R. A. (2005). IOC Medical Comissission Working Group: Position Stand on The Female Atblete Triad. Retrived from httc://www.olympic.ogr.

Ducher, G., Eser, P., Hill, B,. \& Bass, S. (2009). History of amenorrhea compromises some of the exercise-induced benefits in cortical and trabecular bone in the peripheral and axial skeleton: a study in retired elite gymnasts. Bone, 45, 760-767. doi: 10.1016/j.bone.2009.06.021; PMid: 19573632

Elford, K. J., \& Spence, J. H. (2002). The forgotten female: Pediatric and adolescent gynecological concerns and their reproductive consequences. $J$ Pediatr Adolesc Gynecol, 15, 65-77. doi: 10.1016/ S1083-3188(01)00146-2

Goldstein, M. A., Dechant, E. J., \& Beresin, E. V. (2011). Eating disorders. Pediatr Rev., 32(12), 508-521. doi: 10.1542/pir.32-12-508; PMid: 22135421

Greydanaus, D., \& Patel, D. (2002). The female athlete before and beyond puberty. Pediatr Clin N Am., 49, 553-580. doi: 10.1016/S00313955(02)00005-6

Hagen T. (2005). Sports medicine and the adolescent female. J Pediatr Adolesc Gynecol, 18, 9-15. doi: 10.1016/j.jpag.2004.11.005; PMid: 15749579

Ireland, M., \& Ott, S. (2004). Special conserns of the female athlete. Clin Sports Med, 23, 281-289. doi: 10.1016/j.csm.2004.04.003; PMid: 15183572

Jurimae, J., \& Jurimae, T. (2008). Bone Metabolism In Young Female. Kinesiology, 1, 39-49.

Kenney, L. W., Wilmore, H. J., \& Costil, L. D. (2012). Physical Activity for Health and Fitness. In: Physiology of sport and exercise. 5th ed. Champaign. IL: Human Kinetics.

Mitchell, N., \& Ennis, L. A. (2007). Encyclopedia of Title IX and Sports. Westport: Greenwood Press.

Myer, G., \& Ford, K. (2004). Methodological approach and rationale for training to prevent anterior cruciate ligament injuries in female athlete. Scand J Sci Sports, 14, 275-285. doi: 10.1111/j.1600-0838.2004.00410.x; PMid: 15387801

Nativ, A., Loucks, A., Manore, M., Sanborn, C., Sundgot-Borgen, J., \& Warren, M. (2007). ACSM Position Stand; The Female Athlete Triad. Med Sci Sports Exerc, 39, 1867-1882. doi: 
10.1249/mss.0b013e318149f111; PMid: 17909417

Otis, C. L., Drinkwater, B., Johnson, M., Loucks, A., \& Wilmore, J. (1997). American College of Sports Medicine: Position stand; The female athlete triad. Med Sci Sports Exerc, 29, 5-16. doi: http:/ /dx.doi.org/10.1097/00005768199705000-00037

Pfister, G. (2000). Women and the Olympic Games. In B. L. Drinkwater (Ed.), Women in sport. Oxford, GB: Blackwell Science Ltd. doi: 10.1002/9780470757093.ch1

Ponorac, N. (2008). Sport kao rizik za nastanak poremé́aja ishrane, menstrualnog ciklusa i metabolizma kosti [Sport as a risk of eating disorders, menstrual cycle and bone metabolism]. Unpublished doctoral dissertation, University of Banja Luka, Medical Faculty.

Ponorac, N., Rašeta, N., Radovanović, D., Matavulj, A., Popadić-Gaćeša, J. (2011). Bone metabolism markers in sportswomen with menstrual cycle dysfunctions. J Med Biochem, 30(2), 1-5.

Sabatini, S. (2001). The female athlete triad. Am J Med Sci, 322, 193-195. doi: 10.1097/00000441200110000-00007; PMid: 11678514

Sundgot-Borgen, J., \& Larsen, J. (1993). Pathogenic weight-control methods and self-reported eatig disorders in female elite athletes and controls. Scand J Med Sci Sports, 3, 150-155. doi: 10.1111/ j.1600-0838.1993.tb00379.x

Sundgot-Borgen, J., \& Torstveit, M. (2004). Prevalence of eatin disorders in elite athletes is higher than in the general population. Clin J Sport Med, 14, 25-32. doi: 10.1097/00042752200401000-00005; PMid: 14712163

Thein-Nissenbaum, J. (2013). Long term consequences of the female athlete triad. Maturitas, 75(2), 107-112. doi: 10.1016/j. maturitas.2013.02.010; PMid: 23541905

Thomson, R., \& Sherman, T. (1999). Good Athlete traits and characteristice of anorexia nervosa: Are they similar? Eating Disorders, 7, 181-190. doi: 10.1080/10640269908249284

U.S. Department of Health and Human Services. (1996). Physical activity and health: A report of the Surgeon General. Atlanta, GA: U.S. Department of Health and Human Services, Centers for Disease Control and Prevention, National Center for Chronic Disease Prevention and Health Promotion.

Yeager, K., Agostini, A., Nattiv, A., \& Drinkwater, B. (1993). The female athlete triad: disordered eating, amenorrhea, osteoporosis. Med Sci Sports Exerc, 25, 775-777. doi: 10.1249/00005768199307000-00003; PMid:8350697

Received: May 23, 2013

Revision received: Jun 19, 2013

Accepted: Jun 19, 2013

Correspondence to: Nenad Ponorac, $\mathrm{PhD}$

Medica school Save Mrkalja 14 78000 Banja Luka Bosni and Herzegovina Phone: 0038765515264 E-mail: ponorac051@yahoo.com 